\title{
Inactivation by helium cold atmospheric pressure plasma for Escherichia coli and Staphylococcus aureus
}

\author{
Khaled Lotfy ${ }^{1,2}$ (I) $\cdot$ Sayed Mohammed Khalii ${ }^{3,4} \cdot$ Hany Abd El-Raheem ${ }^{5}$
}

Received: 7 February 2019 / Accepted: 3 December 2019 / Published online: 17 December 2019

(c) The Author(s) 2019

\begin{abstract}
A helium cold atmospheric pressure plasma jet (HCAPPJ) driven by a commercial neon power supply was designed and utilized for inactivation bacteria. The generated reactive spices by HCAPPJ were investigated by optical emission spectroscopy. The reactive species of $\mathrm{OH}, \mathrm{OI}, \mathrm{OI}, \mathrm{N}_{2}{ }^{1+}, \mathrm{N}_{2}{ }^{1+}$ and He were identified in the UV-Vis wavelength region. The reactive species was not detected between $200 \mathrm{~nm}$ and $300 \mathrm{~nm}$, as the flow rate of helium gas increased that led to the plasma temperature reducing to a value near to the room temperature. In this work, we studied the impact of HCAPPJ on Gram-positive and Gram-negative bacteria. The survival amounts of the two types of bacteria were decreased vastly when the rate flow rate was equal to $10 \mathrm{~L} / \mathrm{min}$.
\end{abstract}

Keywords Cold plasma $\cdot$ Optical emission spectroscopy $\cdot$ Reactive species $\cdot$ Inactivation bacteria

\section{Introduction}

The expression 'plasma' indicates a quasi-neutral ionized gas, composed initially of free electrons, ions and ground- or excited-state atoms. Furthermore, the comprehensive components of plasma exist in a net neutral charge [1]. However, plasma is the fourth state of matter and forms more than $99 \%$ of the universe. Plasma consists of active particles (e.g., electrons, ions and photons), reactive species (e.g., free radicals) and temporary fields (e.g., heat, acoustic wave, electromagnetic fields). Thus, plasma is a very complicated and active medium. In plasma applications like treating biological materials, plasma components work harmonically.

Khaled Lotfy

khaledlotfy52@yahoo.com

1 Department of Biology, Faculty of Science, Branch of Tayma, Tabuk University, Tabuk, Saudi Arabia

2 King Marriott Higher Institute of Engineering \& Technology, Alexandria, Egypt

3 Physics Department, Faculty of Science, Sohag University, Sohag, Egypt

4 University College, Umm Al-Qura University, Alqunfadah, Saudi Arabia

5 Center for Materials Science, Zewail City of Science and Technology, October Gardens, 6th of October City, Giza, Egypt
This phenomenon has the appropriate effect on materials in contact with the plasma. However, according to the thermodynamic equilibrium between electrons and ions, plasma can be divided into two categories, thermal and nonthermal plasma. In the case of cold plasma, the electron temperature (Te) is much higher than the global gas temperature $(\mathrm{Te} \gg \mathrm{Tg}$ ) and the constituting ions, but, being $\mathrm{Te} \approx \mathrm{Tg}$ with concerning hot plasma, this is the reason for the terms equilibrium and non-equilibrium plasma are referred to hot and cold plasma, respectively.

Nonthermal plasma has drawn enormous attention because of their common potentials for biomedical applications like sterilization, bio-decontamination and cancer handling [2-6]. Moreover, nonthermal (cold) plasma is an ionized gas generated under atmospheric or low-pressure conditions. At atmospheric or low pressures, nonthermal plasma can be induced and sustained using an electric discharge in a gas, using various methods such as the corona, dielectric barrier discharge, or the gliding arc discharge configurations. The generation of a stable plasma plume is considered as an important feature of cold atmospheric pressure plasma jet (CAPPJ) [7]. Many researchers have been studied the effect of cold atmospheric pressure plasma on the thermally sensitive materials using different plasma jet devices [8-10]. CAPPJ has been used in inactivation or death bacteria [11], cancer cells [12, 13], fungi [14, 15], spores [16], parasites [17], phages and viruses [18, 19]. 
The main importance of cold atmospheric plasma is the ability to generate reactive oxygen species (ROS) and reactive nitrogen species (RNS). Furthermore, these species are considered as active biological agents. On the other hand, the temperature of these species can be saved at room temperature. Moreover, CAPPJ has become a novel and safe technology to use for biological applications [20]. The design of a plasma device, gas type, applied voltage, operation time and air conditions play an essential role in the reactive species type and its concentration [21].

After Gram-negative bacteria were exposed to the nonthermal plasma, the cell wall and the outer membrane have been destroyed, a decrease in ATP intracellular and leakage of nucleic acid and protein from the cells of bacteria [22]. Most of the inactivation bacteria impacts regarding nonthermal plasma are attributed to the production of reactive oxygen and nitrogen species (RONS). Recent evidence recommends that RONS are essential agents in antimicrobial and anti-parasitic drugs, tumor medications and wound healing [23]. Therefore, cold atmospheric pressure plasma as a generator of RONS has high promise to be utilized successfully in these vital fields. RONS has a direct influence on the membrane and cell wall of microorganisms. ROS triggers an oxidative stress response leading to lipid peroxidation [24], inactivation of Fe-S-dependent dehydratases, inactivation of mononuclear iron proteins and DNA damage, which ultimately cause detrimental oxidative cell damage [25].

RONS generated by CAPPJ plays a significant role in wound healing, inactivation of microorganism, tumor medication and cardiovascular therapies. Previous research has shown that RONS has a therapeutic role in addition to their destructive role in living cells. On the other hand, it is being necessary for the immune system and serves as signaling molecules [22]. Moreover, the concentration of RONS must remain balanced in the biological systems. There is no doubt that CAPPJ affects this balance by generating a free radical at the treatment site, so that adjustment of the RONS concentration, plasma dose and exposure time are essential condition for the success of using plasma in many applications. Another advantage of cold atmospheric pressure plasma is the control of plasma dose according to the type of application. A low dose of CAPP can achieve the inactivation of bacteria while not damaging mammalian cells. On the other hand, a medium dose of CAPP can be used for wound healing, cell proliferation, growth factor release and apoptosis in cancer. Furthermore, mammalian cell death and necrosis can be operated at a high dose of CAPP. The principal aim of this work is to investigate the impacts of a helium cold atmospheric pressure plasma jet (HCAPPJ) on bacterial decontamination. This study compared the inactivation of HCAPPJ against E. coli and Staphylococcus aureus as an example for Gram-negative and Gram-positive bacteria, respectively.

\section{Materials and methods}

In the current study, the helium cold atmospheric pressure plasma jet (HCAPPJ) system was designed and used in bacteria inactivation. The HCAPPJ is mainly composed of a commercial neon power supply, voltage controller, stainless steel electrodes, dielectrics and helium gas. The design of the CAPPJ as can be seen in Fig. 1 was described in an earlier study [26-28]. The high-voltage power supply is a commercially available transformer for neon light. The neon power supply is appropriated in the cold atmospheric plasma to produce the plasma jet to cut the overall cost of the system by substituting the expensive RF power supply which representing the major cost. The output of the high-voltage neon power supply is $30 \mathrm{~mA}, 10 \mathrm{kV}$, and $20 \mathrm{kHz}$, which lie in the range of very depressed frequency of RF. This power supply has an overload, open circuit, earth leakage and short-circuit protection. The input of this power supply is connected to $220 \mathrm{~V}, 12 \mathrm{~A}$ voltage controller. The voltage controller regulates the primary voltage of the high-voltage transformer. The electrode system of the HCAPPJ made up of two parallel stainless steel disks detached by Teflon insulator. The external electrode and the inside electrode have represented the cathode and the anode, respectively. However, the cathode and the anode have similar thickness and diameter of $15 \mathrm{~mm}$ and $2 \mathrm{~mm}$, respectively, but the Teflon disk has a $1 \mathrm{~mm}$ thickness and $15 \mathrm{~mm}$ in diameter.

The two electrodes and Teflon disk have center hole of $1 \mathrm{~mm}$ and $1.2 \mathrm{~mm}$ diameter, respectively, though center hole helium gas is flowing. The gas flow system is liable for transporting the gas to the plasma jet at the convenient flow rate. It is composed of the gas storage cylinder, binary-stage gas

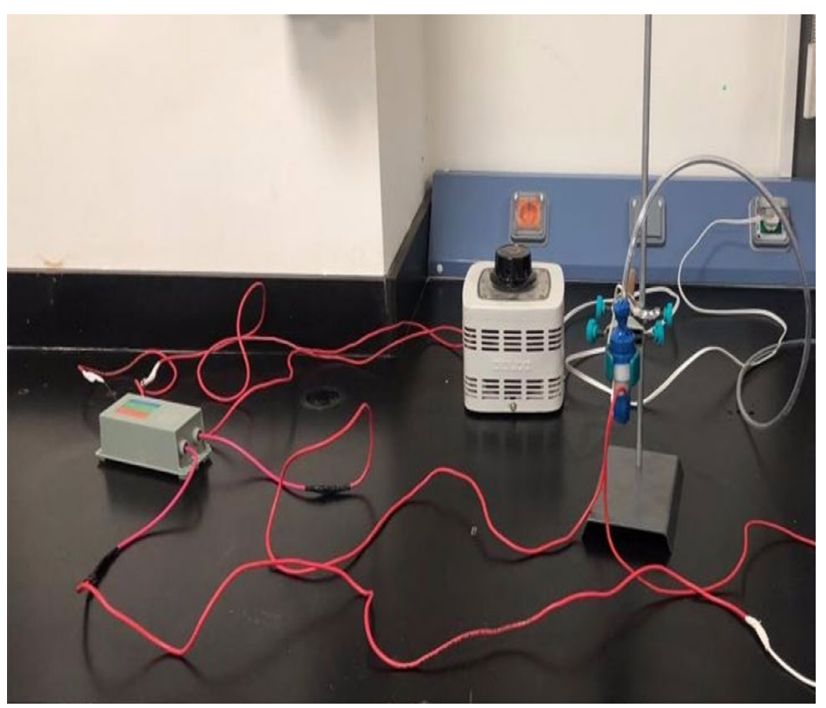

Fig. 1 Cold atmospheric pressure plasma jet system 
flow controller and gas connection rubber hose. In this work, helium gas with a commercial grade of $99.998 \%$ was used to operate the plasma jet system. The helium flow rate was controlled by the binary-stage gas flow controller. Once the helium gas is introduced through the two electrodes and the suitable high voltage is applied between them, the helium atoms are ionized by driving off electrons so that the ionization of neighboring helium species occurred by a collision with free electrons. After the series of these reactions, the helium gas converts to the plasma state.

An optical emission spectrometer detects photon emission in this region. Spectra obtained provide valuable information about species present within the plasma and their electron excitation, which in turn enables the calculation of vibrational and electron temperature within the plasma. The UV-visible emission spectra from the plasma reactor were obtained with a spectrometer which consists of a lens connected to a detector via fiber optic cable. In this work, the spectroscopy with the model number of HR4000CGUV-NIR (Ocean Optics) was employed. The spectra were registered in the longitudinal geometry with the device probe in an axial position, at a distance of $10 \mathrm{~mm}$ from the nozzle outlet with an acquisition time of $1 \mathrm{~s}$. However, the voltage measurement was taken using a high-voltage probe P6015 Tektronix HV probe with a digital oscilloscope (Tektronix MSO4032).

The Reynolds number (Rn) is defined for many various conditions in which a fluid is in relative motion to the interior surface of the tube. The Reynolds number in a tube is commonly represented as the subsequent equation [29, 30],

$R_{\mathrm{n}}=\frac{v \rho D}{\mu}=2.2 \times 10^{-2} \frac{\rho}{\mu} \frac{Q}{r_{\mathrm{D}}}$

where $\nu$ is the fluid velocity $(\mathrm{m} / \mathrm{s}), \rho$ is the fluid density $(\mathrm{kg} /$ $\mathrm{m}^{3}$ ), $D$ is the diameter (m) of the tube, and $\mu$ is the viscosity (kg/m.s).

However, the fluid velocity can be determined by the following equation,

$\nu=\frac{q}{A}$

where $q$ is the flow rate in units of $\mathrm{m}^{3} / \mathrm{s}$, and the following equation calculated the tube cross section,

$A=\pi\left(\frac{D}{2}\right)^{2}$

The fluid velocity is calculated by the following equation,

$v=2.12 \times 10^{1}\left(\frac{Q}{r_{\mathrm{D}}^{2}}\right)$ where $Q$ is the volumetric flow rate in liters per minute (lpm) and $r_{D}$ is an inner diameter in (mm)

In this experiment to study the impact of HCAPPJ on inactivation microorganism, Staphylococcus aureus and Escherichia coli were used. Several colonies were picked up from an overnight culture of each isolate, suspended into $3 \mathrm{ml}$ of brain heart infusion broth (BHI), and then kept for $24 \mathrm{~h}$ at $37^{\circ} \mathrm{C}$. However, after $24 \mathrm{~h}$ of incubation, the bacterial suspension was diluted with the sterile physiological solution to $5 \times 10^{8} \mathrm{CFU} / \mathrm{ml}$, which was compared with 0.5 McFarland standard tubes. After the suspension was prepared, $0.1 \mathrm{ml}$ of this suspension, containing $5 \times 10^{8} \mathrm{CFU} / \mathrm{ml}$ bacteria, was spread on the nutrient agar via the spreading method by a sterile swab in a standard Petri dish. The dishes were stored in an aseptic location to dry for $10 \mathrm{~min}$ and then exposed to the plasma jet.

After the plasma treatment, the samples were put into test tubes containing $5 \mathrm{~mL}$ of germ-free water and mixed for $5 \mathrm{~min}$ by a vortex mixer. The obtained suspensions were then serially diluted and dispersed onto agar plates, and the CUF number was counted after incubation for $36 \mathrm{~h}$ at $37 \pm \mathrm{C}$. In this work, two independent kits of specimens were prepared, and each dilution was dispersed onto two agar dishes, which indicates that each colony counting result was an average of the four agar dishes [31].

\section{Result and discussions}

In this work, to determine the optimum conditions to use the HCAPPJ in biological applications a thermocouple was used to determine the plasma temperature. The effect of the distance from the jet nozzle, the helium flow rate and the applied voltage on the plasma temperatures was examined. The effect of the distance from the jet nozzle on the plasma temperatures at $3.5 \mathrm{kV}$ and $14 \mathrm{1} / \mathrm{min}$ as a constant applied voltage and constant helium flow rate, respectively, can be seen in Fig. 2. As was expected, the plasma temperature decreases continuously by increasing the axial position. However, the gas temperatures of the plasma jet at different helium flow rates at $3.5 \mathrm{kV}$ and $7 \mathrm{~mm}$ as a constant applied voltage and constant distance from the jet nozzle, respectively, can be shown in Fig. 3. From this figure, the gas temperature decreases continuously as the flow rate of helium increases from $10 \mathrm{l} / \mathrm{min}$ to $16 \mathrm{l} / \mathrm{min}$. On the other hand, the effect of the applied voltage on the plasma temperatures at $7 \mathrm{~mm}$ and $14 \mathrm{l} / \mathrm{min}$ as a constant of the distance from the jet nozzle and constant helium flow rate, respectively, can be illustrated in Fig. 4. However, from this figure, the increase in the applied voltage to the carrier gas will produce an increase in ionizing rate, which will lead to a higher gas temperature [32]. 


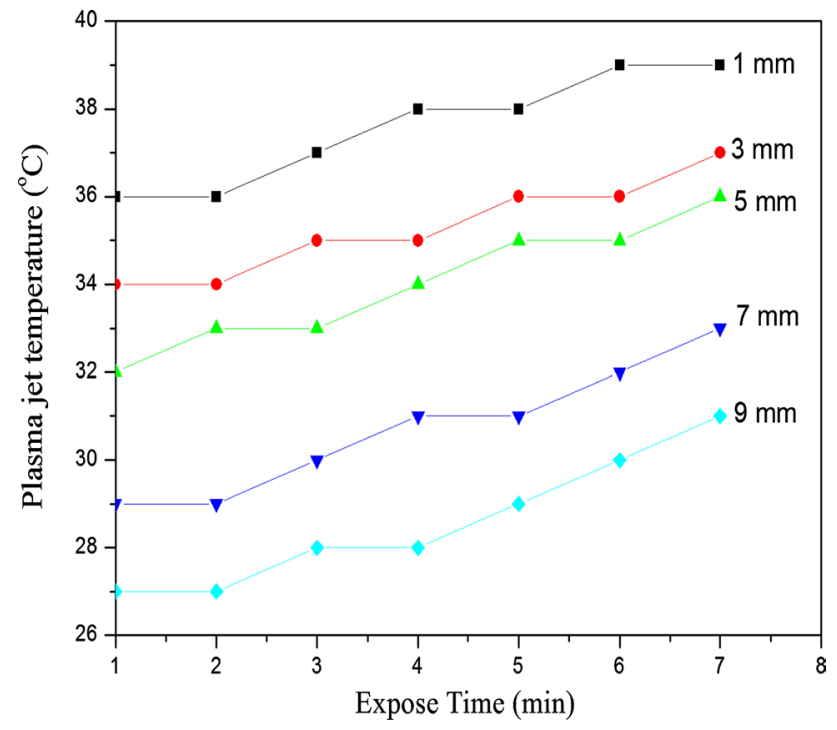

Fig. 2 The plasma jet temperature at different distances from jet nozzle

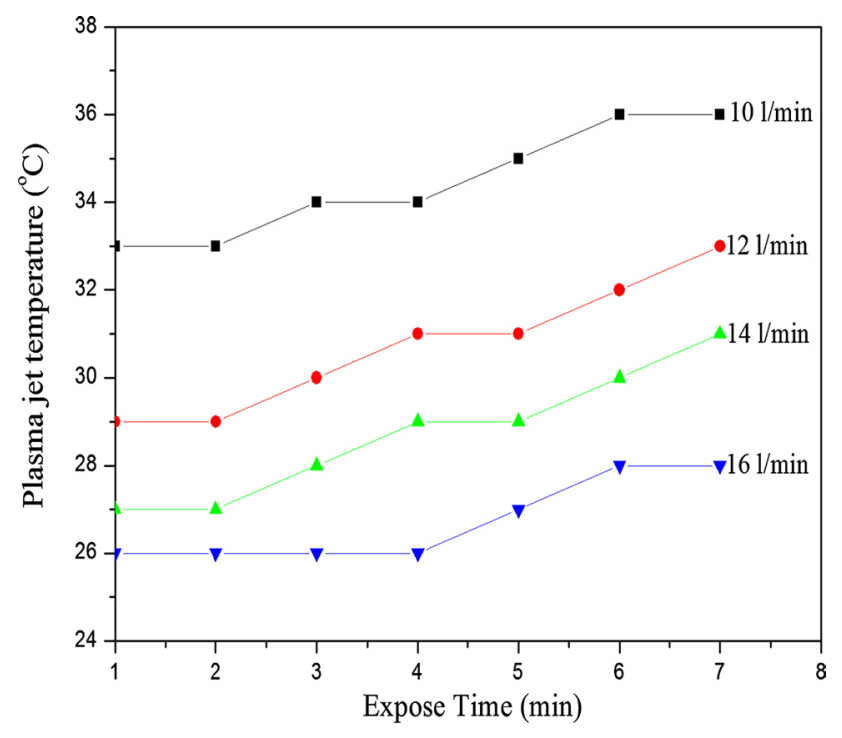

Fig. 3 The plasma jet temperature at different helium flow rates

By increasing the input voltage, the higher ion current increases which led to the increase in temperature of gas plasma so that plasma temperature can be controlled by varying the applied voltage which applied to the gas between the two electrodes. Plasma temperature decreases to near room temperature when the gas flow rate increases [33]. However, the helium plasma plume entirely depends on the high flow rates of feed gas to help reduce the gas temperature. Furthermore, it was evident that the current plasma has a low temperature near the nozzle at the most discharge conditions concerning DC plasma plume using the same electrodes design. The DC plasma produces higher

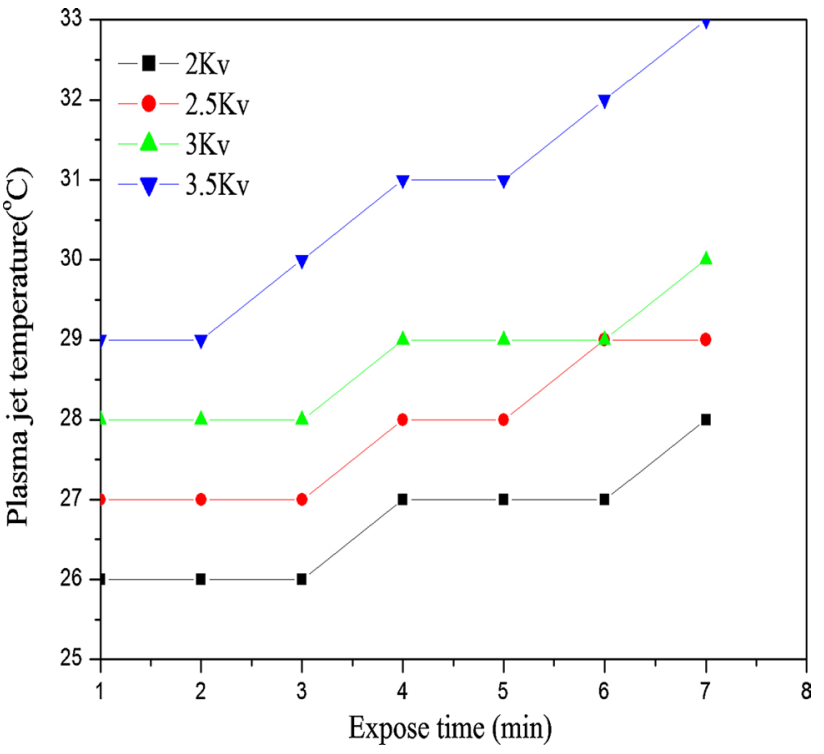

Fig. 4 The plasma jet temperature at different input voltages

gas temperature near the jet nozzle because the cathode heat occurred by the continuous high ion current [34]. Moreover, cold atmospheric plasma can be used in sensitive surface treatment by choosing suitable conditions.

Furthermore, the gas temperature of nonthermal plasma depends on: (1) the input voltage which applied between cathode and anode, (2) the distance from the nozzle and (3) the gas flow rate. The region near the plasma nozzle is an ideal area for treating biological cells because it contains a high concentration of reactive species and the low plasma temperature, resulting in effective nondestructive treatment $[35,36]$. Furthermore, the gas temperature increases continuously for all conditions by increasing the operation time.

The plume plasma of HCAPPJ was observed by Ocean optical emission spectroscopy to investigate the behavior of atomic and molecular helium and other constituent species. The optical emission spectrum of the helium plasma jet at $3.5 \mathrm{kV}, 14 \mathrm{~L} / \mathrm{m}$ and $7 \mathrm{~mm}$, which represented applied voltage, helium flow rate and distance from nozzle, respectively, is illustrated in Fig. 5. In this figure, the active species of $\mathrm{OH}, \mathrm{OII}, \mathrm{OI}, \mathrm{N}_{2}{ }^{1+}, \mathrm{N}_{2}{ }^{1+}$ and $\mathrm{He}$ are indented in the UV-Vis wavelength range. The interaction between the helium plasma jet and the surrounding air leads to form these active species [37].

From this figure, it can be observed that there is no obvious UV emission between $200 \mathrm{~nm}$ and $300 \mathrm{~nm}$. The disappearance of these peaks infers that the UV radiation did not contribute to the inactivation process and did not share in any damage which will be caused to the cells of bacteria using this jet. The spectral lines of the hydroxyl group and nitrogen second positive system can be found in the UV region only. Typically, the emission lines at wavelengths 


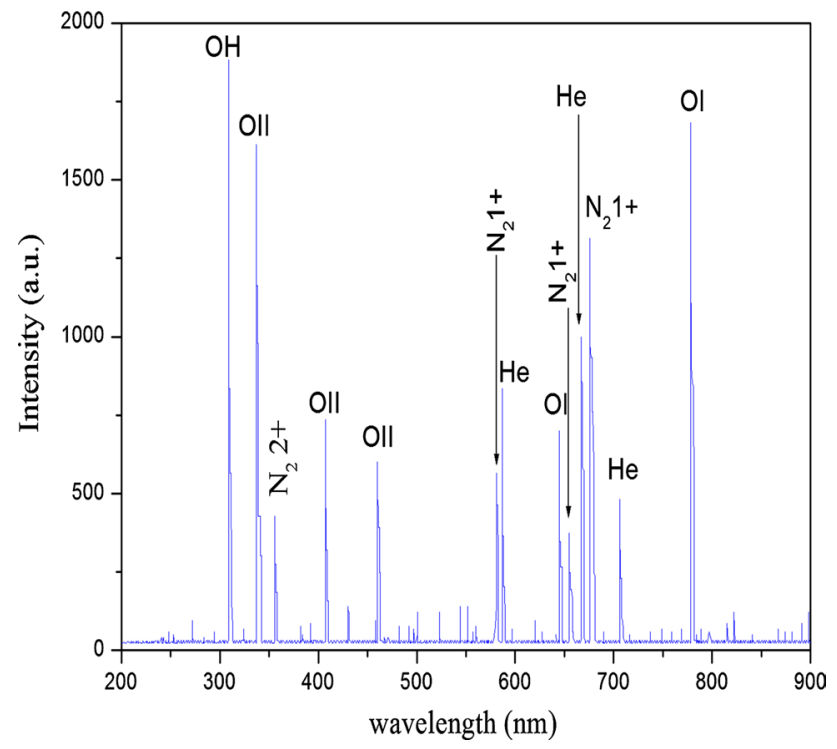

Fig. 5 Emission spectra from 200 to $900 \mathrm{~nm}$ corresponding to $14 \mathrm{l} /$ min, $3.5 \mathrm{kV}$ and $7 \mathrm{~mm}$ as helium flow rate, the applied voltage and distance from the jet nozzle, respectively

391 and $354 \mathrm{~nm}$ correspond to $\mathrm{OH}$ and $\mathrm{N}_{2}{ }^{2+}$, respectively. However, the spectral lines of OII only can be found in the UV-Vis region, this reactive species can be observed at 337, 406 and $459 \mathrm{~nm}$. Moreover, the reactive species of $\mathrm{N}_{2}{ }^{1+}$, $\mathrm{OI}$ and $\mathrm{He}$ can be found in the Vis region only. The reactive atomic oxygen OI can be detected at 645 and $777 \mathrm{~nm}$ $[38,39]$. The 580, 654 and $677 \mathrm{~nm}$ observed peaks are represented in the $\mathrm{N}_{2}$ first positive system $\left(\mathrm{N}_{2}{ }^{1+}\right)[38,40]$. Besides, the reactive species of $\mathrm{He}$ can be found at 587 and $706 \mathrm{~nm}$.

The change in the intensity peaks of $\mathrm{OH}, \mathrm{OII}, \mathrm{OI}, \mathrm{N}_{2}{ }^{1+}$, $\mathrm{N}_{2}{ }^{1+}$ and He species by varying the applied voltage, the distance from the nozzle and the helium flow rate was examined. The change in the intensity peaks of reactive species by varying the distance from the jet nozzle at $3.5 \mathrm{kV}$ and $14 \mathrm{l} /$ min as a constant applied voltage and constant helium flow rate, respectively, is represented in Fig. 6. From this figure, it can be shown that as the distance from the nozzle increased, the spectral line intensities of five species decreased. These results agree with the result obtained by Mashayekh et al. 2015; they concluded that, by increasing the distance from the nozzle, the active species radicals will be recombined and their concentration will diminish with distance [32]. However, from Fig. 7, the intensity peaks of reactive species increase by increasing the applied voltage at $7 \mathrm{~mm}$ and $14 \mathrm{l} / \mathrm{min}$ as a constant of the distance from the jet nozzle and constant helium flow rate, respectively. This behavior can be attributed to the effect of increasing the applied voltage leading to enhanced discharge current by creating higher reactive species concentrations when more intense ionization wave enters inside the plasma plume [41].

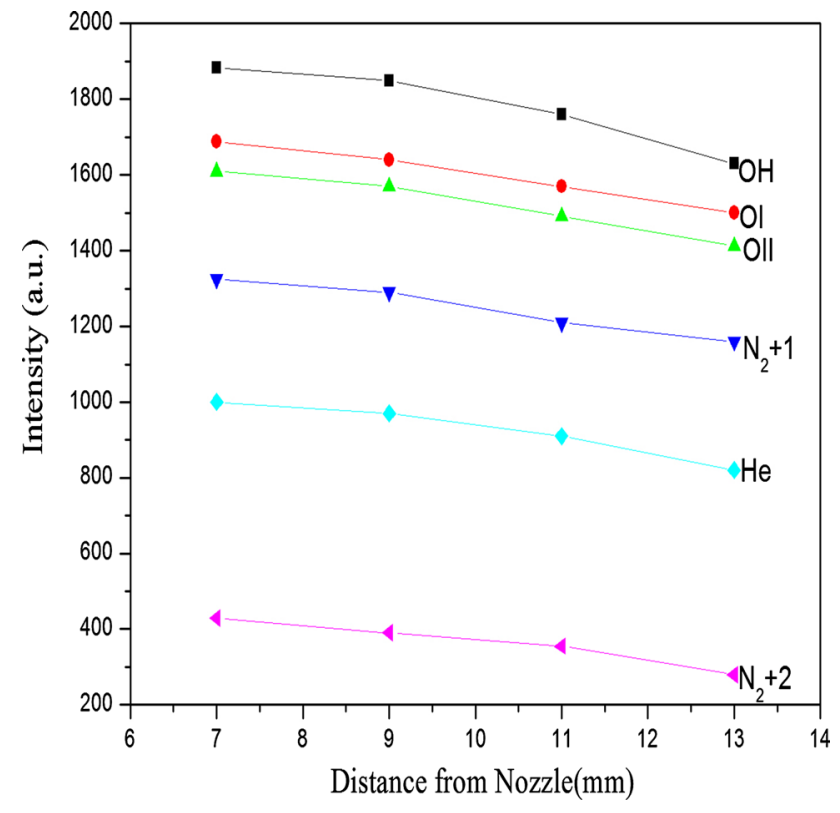

Fig. 6 Emission intensities of a OH, O I, O II, N2 $2^{+1}$, He and $\mathrm{N}^{+2}$ as a function of distance from nozzle

On the other hand, from Fig. 8, the intensity peaks of reactive species increase as the helium flow rate is increased at $3.5 \mathrm{kV}$ and $7 \mathrm{~mm}$ as a constant applied voltage and constant distance from the jet nozzle, respectively. This behavior can be attributed to the decrease in air concentration, which lies in the plasma region by increasing helium flow rate. The lower air concentration can lead to higher local electron concentration. These explain the

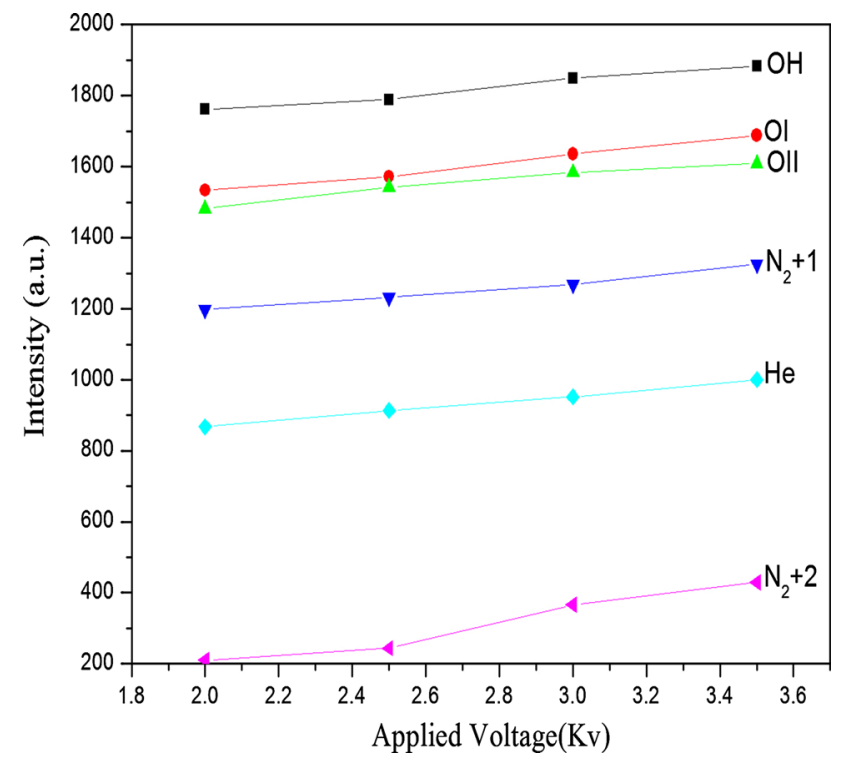

Fig. 7 Emission intensities of a OH, O I, O II, N2 $2^{+1}, \mathrm{He}$ and $\mathrm{N} 2^{+2}$ as a function of applied voltage 


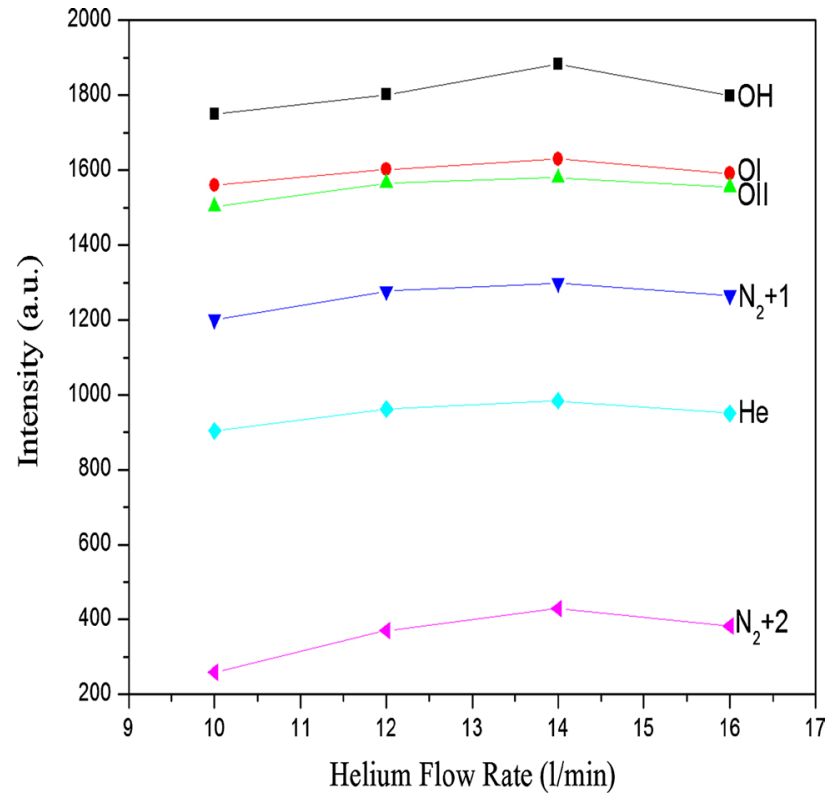

Fig. 8 Emission intensities of a OH, O I, O II, N2 $2^{+1}$ He and $\mathrm{N} 2^{+2}$ as a function of helium flow rate

higher emission intensity from the excited species [42, 43]. As observed from this figure, the intensity peaks have reached the maximum at $14 \mathrm{l} / \mathrm{min}$, and then, the drop of intensity has occurred after that. These results can be attributed to the effect of Reynolds number. If the $R_{n}$ is relatively small, such as $\mathrm{Rn}<2000$, the flow is laminar. If it is large, i.e., $R_{n}>4000$, the flow is turbulent [44]. In this experiment at $16 \mathrm{l} / \mathrm{min}$, the $\mathrm{R}_{\mathrm{n}}$ is 4125 , and this causes the flow rate to become turbulent and results in instabilities and deformations of the gas flow rate. However, it can be concluded that the decrease in reactive species intensity can be attributed to the deformations, which have been occurred in the gas flow rate.

Reactive species, which was generated by nonthermal plasma, play an essential role in cell death of microorganism [45]. These reactive species are such as ozone $\left(\mathrm{O}_{3}\right)$, atomic oxygen $(\mathrm{O})$, superoxide $\left(\mathrm{O}_{2}^{-}\right)$, hydroxyl radicals $(\mathrm{OH})$, nitric oxide (NO), hydrogen peroxide $\left(\mathrm{H}_{2} \mathrm{O}_{2}\right)$, and other reactive molecules, all of which are known to have bactericidal effects [46]. The particles listed above attack the bacterial structure in various ways. Reactive species such as atomic oxygen and $\mathrm{OH}$ physically etch the outer cell capsule, thus exposing the cellular membrane [47]. Nonthermal plasmainduced radicals also attack the unsaturated fatty acids transported by the phospholipid bilayer, which are susceptible to attack by most reactive species [48]. Oxidation of the protein content of cellular components, by atomic oxygen, $\mathrm{OH}$, or $\mathrm{O}_{2}{ }^{-}$alters their structure and causes functional changes that may disrupt cell metabolism, preventing necessary protein replication and hence stunting cellular metabolism [49].

Through this work, the optimum conditions of inactivation bacteria using HCAPPJ have been determined. The optimum conditions were obtained by study of helium cold plasma characterization. The irradiation time of helium atmospheric plasma to the same kinds of bacteria was $60 \mathrm{~s}$. At these conditions, the high concentration of reactive species can be obtained; also, we can avoid the hyperthermia effect. Moreover, the first mechanism by which tissue is thermally affected can be attributed to conformational changes of molecules. These effects, accompanied by bond destruction and membrane alterations, are summarized in the single term ranging from approximately 42 to $50{ }^{\circ} \mathrm{C}$ [50]. The treatment temperature in this work was in the range of $26-36{ }^{\circ} \mathrm{C}$. From this result, it can be observed that the survival amounts of the two bacteria decrease vastly when the rate flow rate equals $101 / \mathrm{min}$, as can be seen in Fig. 9, which means the numbers of alive cells decrease rapidly in the two samples.

Table 1 shows the effect of flow rate of helium at $3.5 \mathrm{kV}$ as applied voltage and $7 \mathrm{~mm}$ as a distance from the nozzle on the number of survivors for the two types of bacteria. Further, as the flow rate increases, this led to the decrease in numbers of alive cells decrease. The maximum decrease in alive cells has been recorded at $14 \mathrm{l} / \mathrm{min}$. The higher value of reactive species at $14 \mathrm{l} / \mathrm{min}$ of atmospheric helium plasma can be interpreted by the decrease in alive cells. On the other hand, the numbers of alive cells increase at $16 \mathrm{l} /$ min of the helium atmospheric plasma flow rate. The bactericidal effects occur when the particular reactive molecules are present in high concentrations.

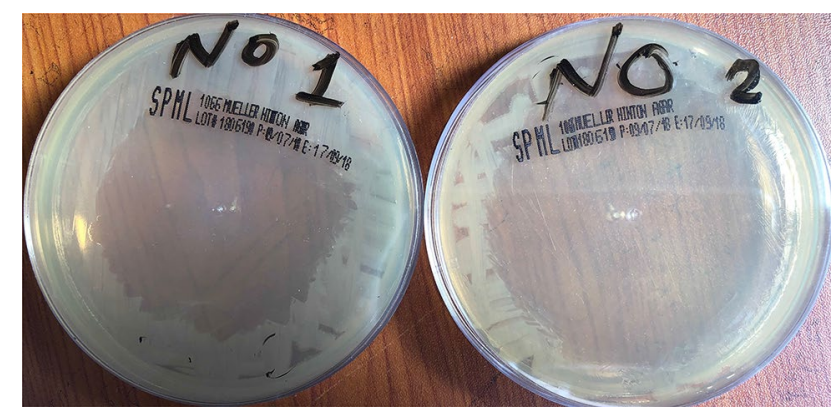

Fig. 9 The effect of HCAPPJ on No. 1: S. aureus and No. 2: E. coli

Table 1 The survivors number of E. coli and S. aureus as a function of helium flow rate

\begin{tabular}{lll}
\hline $\begin{array}{l}\text { Flow rate } \\
(\mathrm{L} / \mathrm{min})\end{array}$ & $\begin{array}{l}\text { Number of survi- } \\
\text { vors (CFU/ml) }\end{array}$ \\
\cline { 2 - 3 } & E. coli & S. aureus \\
\hline 0 & $5 \times 10^{8}$ & $5 \times 10^{8}$ \\
10 & $2 \times 10^{4}$ & $6 \times 10^{4}$ \\
12 & $3 \times 10^{3}$ & $1 \times 10^{4}$ \\
14 & $6 \times 10^{2}$ & $7 \times 10^{3}$ \\
16 & $2 \times 10^{3}$ & $6 \times 10^{3}$ \\
\hline
\end{tabular}


In low concentrations, most of the reactive species have beneficial effects on the cell functionality, e.g., inhibiting peroxidation or neutralization of other reactive components [51]. Reactive species either reacted with the cell envelope or damaged intracellular components. Gram negative was inactivated by cell envelope damage-induced leakage, while Gram positive was mainly eliminated by intracellular damage [52]. The results obtained show that HCAPPJ is more effective against Gram-negative than Gram-positive bacteria. The differences in cell wall structure can be critical for the differential sensitivity of Gramnegative and Gram-positive bacteria. The structure of the cell envelope concerning Gram-negative bacteria consists of a thin layer of peptidoglycan and lipopolysaccharide, while in the case of a Gram positive the cell envelope consists of a thick rigid layer of peptidoglycan. However, these differences in the cell envelope confer different properties to the cell, in particular response to external stresses, including heat, UV radiation and antibiotics [53]. That means, HCAPPJ induced biological effects which are cell-/ bacteria-type dependency [54].

\section{Conclusions}

A helium cold atmospheric pressure plasma jet (HCAPPJ) was designed and operated to study the effect of nonthermal plasma on bacteria inactivation. This design exhibits many advantageous features, including i) the production of a large amount of reactive species, ii) operate at low temperature and iii) a simple design and operation. To study the effects of HCAPPJ on bacteria inactivation, initially, the plasma temperature was measured to make sure that the used cold atmospheric pressure plasma jet is safe and has powerful impacts. This measurement is essential and required in the biological application. The plasma temperature and the concentration reactive species depend on the applied voltage, the distance from the nozzle and the helium flow rate. The concentration of reactive species increased by increasing the flow rate from 10 to $14 \mathrm{l} / \mathrm{min}$, and the decrease in the reactive species concentration has occurred when this value is exceeded. The bacteria exposed to plasma showed a decrease in the survival amounts of the two types of bacteria with increasing flow rate of helium gas, suggesting that the RONS played a significant role in the inactivation process. The result revealed that HCAPPJ has more effective against Gram-negative than Gram-positive bacteria. The optimum condition of our HCAPPJ system to bacteria inactivation is $14 \mathrm{l} / \mathrm{min}, 3 / 5 \mathrm{kV}$ and $7 \mathrm{~mm}$, which represent the helium flow rate as the applied voltage and the distance from the nozzle, respectively.
Open Access This article is licensed under a Creative Commons Attribution 4.0 International License, which permits use, sharing, adaptation, distribution and reproduction in any medium or format, as long as you give appropriate credit to the original author(s) and the source, provide a link to the Creative Commons licence, and indicate if changes were made. The images or other third party material in this article are included in the article's Creative Commons licence, unless indicated otherwise in a credit line to the material. If material is not included in the article's Creative Commons licence and your intended use is not permitted by statutory regulation or exceeds the permitted use, you will need to obtain permission directly from the copyright holder. To view a copy of this licence, visit http://creativecommons.org/licenses/by/4.0/.

\section{References}

1. Pankaj, S.K., Bueno-Ferrer, C., Misra, N.N., Milosavljević, V., O’Donnell, C.P., Bourke, P., Keener, K.M., Cullen, J.P.: Applications of cold plasma technology in food packaging. Trends Food Sci. Technol. 35, 5-17 (2014)

2. Keidar, M.: Plasma for cancer treatment. Plasma Sources Sci. Technol. 24, 033001 (2015)

3. Gazeli, K., Noel, C., Clement, F., Dauge, C., Svarnas, P., Belmonte, T.: A study of helium atmospheric-pressure guided streamers for potential biological applications. Plasma Sources Sci. Technol. 22, 025020 (2013)

4. Isbary, G., Shimizu, T., Li, Y., Stolz, W., Thomas, H., Morfill, G., Zimmermann, J.: Cold atmospheric plasma devices for medical issues. Expert Rev. Med. Devices 10, 367 (2013)

5. Nayak, G., Aboubakr, A., Goyal, M., Bruggeman, J.: Reactive species responsible for the inactivation of feline calicivirus by a two-dimensional array of integrated coaxial microhollow dielectric barrier discharges in air. Plasma Process. Polym. 15(1), 1700119 (2018)

6. Vandamme, M., Robert, E., Lerondel, S., Sarron, V., Ries, D., Dozias, S., Sobilo, J., Gosset, D., Kieda, C., Legrain, B., Pouvesle, J.M., Pape, A.L.: ROS implication in a new antitumor strategy based on non-thermal plasma. Int. J. Cancer 130, 2185 (2012)

7. Liu, F., Zhang, B., Fang, Z., Wan, M., Wan, H., Ostrikov, K.: Jet to-jet interactions in atmospheric-pressure plasma jet arrays for surface processing. Plasma Process Polym. 15(1), 1700114 (2018)

8. Hong, Y.C., Uhm, H.S., Yi, W.J.: Atmospheric pressure nitrogen plasma jet: observation of striated multilayer discharge patterns. Appl. Phys. Lett. 93, 051504 (2008)

9. Nie, Q.-Y., Ren, C.-S., Wang, D.-Z., Zhang, J.-L.: A simple cold Ar plasma jet generated with a floating electrode at atmospheric pressure. Appl. Phys. Lett. 93, 011503 (2008)

10. Deng, X.T., Shi, J.J., Kong, M.G.: Protein destruction by a helium atmospheric pressure glow discharge: Capability and mechanisms. J. Appl. Phys. 101, 074701 (2007)

11. Ahn, H.J., Kim, K.I., Kim, G., Moon, E., Yang, S.S., Lee, J.S.: Atmospheric-pressure plasma jet induces apoptosis involving mitochondria via generation of free radicals. PLoS One 6 , e28154 (2011)

12. Ishaq, M., Evans, M.M., Ostrikov, K.K.: Effect of atmospheric gas plasmas on cancer cell signaling. Int. J. Cancer 134, 15171528 (2014)

13. Ermolaeva, S.A., Sysolyatina, E.V., Kolkova, N.I., Bortsov, P., Tuhvatulin, A.I., Vasiliev, M.M., Mukhachev, A.Y., Petrov, O.F., Tetsuji, S., Naroditsky, B.S., Morfill, G.E., Fortov, V.E., Grigoriev, A.I., Zigangirova, N.A., Gintsburg, A.L.: Non-thermal argon plasma is bactericidal for the intracellular bacterial pathogen Chlamydia trachomatis. J. Med. Microbiol. 61, 793-799 (2012) 
14. Alshraiedeh, N.H., Alkawareek, M.Y., Gorman, S.P., Graham, W.G., Gilmore, B.F.: Atmospheric pressure non-thermal plasma inactivation of MS2 bacterio-phage: effect of oxygen concentration on virucidal activity. J. Appl. Microbiol. 115, 1420-1426 (2013)

15. Zimmermann, J.L., Dumler, K., Shimizu, T., Morfill, G.E., Wolf, A., Boxhammer, V., Schlegel, J., Gansbacher, B., Anton, M.: Effects of cold atmospheric plasmas on adenoviruses in solution. J. Phys. D Appl. Phys. 44, 505201 (2011)

16. Balasubramanian, M., Sebastian, A., Peddinghaus, M., Fridman, G., Fridman, A., Gut-sol, A., Friedman, G., Ari, B.: Dielectric barrier discharge plasma in coagulation and sterilization. Blood 108, 89b (2006)

17. Yang, B., Chen, J.R., Yu, Q.S., Li, H., Lin, M.S., Mustapha, A., Hong, L., Wang, Y.: Oral bacterial deactivation using a low-temperature atmospheric argon plasma brush. J. Dent. 39, 48-56 (2011)

18. Sun, P., Pan, J., Tian, Y., Bai, N., Wu, H.Y., Wang, L.X., Cailan, Y., Jue, Z., Weidong, Z., Becker, K., Fang, J.: Tooth whitening with hydrogen peroxide assisted by a direct-current cold atmosphericpressure air plasma micro jet. IEEE Trans. Plasma Sci. 38, 18921896 (2010)

19. Heinlin, J., Isbary, G., Stolz, W., Morfill, G., Landthaler, M., Shimizu, T., Steffes, B., Nosenko, T., Zimmermann, J., Karrer, S.: Plasma applications in medicine with a special focus on dermatology. J. Eur. Acad. Dermatol. 25, 1-11 (2011)

20. Niemira, B.A.: Cold plasma decontamination of foods. Annu. Rev. Food Sci. Technol. 3, 125-142 (2012)

21. Moiseev, T., Misra, N.N., Patil, S., Cullen, P.J., Bourke, P., Keener, K.M., Mosnier, J.P.: Post-discharge gas composition of a large-gap DBD in humid air by UV-Vis absorption spectroscopy. Plasma Sources Sci. Technol. 23, 065033 (2014)

22. Kvam, E., Davis, B., Mondello, F., Garner, A.L.: Nonthermal atmospheric plasma rapidly disinfects multidrug-resistant microbes by inducing cell surface dam-age. Antimicrob. Agents Chemother. 56, 2028-2036 (2012)

23. Graves, D.B.: The emerging role of reactive oxygen and nitrogen species in redox biology and some implications for plasma applications to medicine and biology. J. Phys. D Appl. Phys. 45, 263001 (2012)

24. Joshi, S.G., Cooper, M., Yost, A., Paff, M., Ercan, U.K., Fridman, G., Friedman, G., Fridman, A., Brooks, A.D.: Nonthermal dielectric-barrier discharge plasma-induced inactivation involves oxidative DNA damage and membrane lipid peroxidation in Escherichia coli. Antimicrob. Agents Chemother. 55, 1053-1062 (2011)

25. Imlay, J.A.: The molecular mechanisms and physiological consequences of oxidative stress: lessons from a model bacterium. Nat. Rev. Microbiol. 11, 443-454 (2013)

26. Lotfy, K.: Cold plasma jet construction to use in medical, biology and polymer applications. J. Mod. Phys. 8, 1901-1910 (2017)

27. Lotfy, K.: Effects of cold atmospheric plasma jet treatment on the seed germination and enhancement growth of watermelon. Open J. Appl. Sci. 7, 705-719 (2017)

28. Lotfy, K., Al-Harbi, N.A., Abd El-Raheem, H.: Plasma chem plasma process atmospheric pressure nitrogen plasma jet for enhancement germination of wheat seeds. Plasma Chem. Plasma Process. 39, 897-912 (2019)

29. Jhin, S., Kim, Y., Lee, W.Y., Jin, D.J., Yu, H.-K., Kim, H., Koo, J.H., Cho, G.: Gas-flow rate and reynolds number in a tube of plasma jet device. In: Abstracts IEEE International Conference on Plasma Science (ICOPS), pp. 1, 2013. IEEE (2013)

30. Jin, D.J., Uhm, H.S., Cho, G.: Influence of the gas-flow Reynolds number on a plasma column in a glass tube. Phys. Plasmas 20(8), 083513 (2013)

31. Liu, X., Hong, F., Guo, Y., Zhang, J., Shi, J.: Sterilization of Staphylococcus Aureus by an atmospheric non-thermal plasma jet. Plasma Sci. Technol. 15(5), 439-442 (2013)
32. Mashayekh, Shahriar, Rajaee, Hajar, Akhlaghi, Morteza, Shokri, Babak, Hassan, Zuhir M.: Atmospheric-pressure plasma jet characterization and applications on melanoma cancer treatment (B/16F10). Phys. Plasmas 22, 093508 (2015)

33. Hong, Y.C., Kang, W.S., Hong, Y.B., Yi, W.J., Uhm, H.S.: Atmospheric pressure air-plasma jet evolved from microdischarges: eradication of E. coli with the jet. Phys. Plasmas 16, 123502 (2009)

34. Dudek, D., Bibinov, N., Engemann, J., Awakowicz, P.: Direct current plasma jet needle source. J. Phys. D 40, 7367 (2007)

35. Benedikt, J., Focke, K., Yanguas-Gil, A., von Keudell, A.: Atmospheric pressure microplasma jet as a depositing tool Appl. Phys. Lett. 89, 251504 (2006)

36. Fridman, G., Brooks, A., Balasubramanian, M., Fridman, A., Gutsol, A., Vasilets, V., Ayan, H., Friedman, G.: Comparison of direct and indirect effects of non-thermal atmospheric-pressure plasma on bacteria. Plasma Process. Polym. 4, 370 (2007)

37. Kim, S.J., Chung, T.H., Joh, H.M., Cha, J.-H., Eom, I.S., Lee, H.-J.: Characteristics of multiple plasma plumes and formation of bullets in an atmospheric-pressure plasma jet array. IEEE Trans. Plasma Sci. 43(3), 753-759 (2015)

38. Kolb, J., Mohamed, A., Price, R., Swanson, R., Bowman, A., Chiavarini, R., Stacey, M., Schoenbach, K.: Cold atmospheric pressure air plasma jet for medical applications. Appl. Phys. Lett. 92(24), 241501-241503 (2008)

39. Hong, Y.C., Cho, S.C., Kim, J.H., Uhm, H.S.: A long plasma column in a flexible tube at atmospheric pressure. Phys. Plasmas 14(7), 074502-074505 (2007)

40. Huang, X.J., Xin, Y., Yang, L., Yuan, Q.H., Ning, Z.Y.: Spectroscopic study on rotational and vibrational temperature of $\mathrm{N}_{2}$ and $\mathrm{N}_{2}{ }^{+}$in dual-frequency capacitively coupled plasma. Phys. Plasmas 15(7), 113504 (2008)

41. Kim, D.Y., Kim, S.J., Joh, H.M., Chung, T.H.: Characterization of an atmospheric pressure plasma jet array and its application to cancer cell treatment using plasma activated medium. Phys. Plasmas 25, 073505 (2018)

42. Boselli, M., Colombo, V., Gherardi, M., Laurita, R., Liguori, A., Sanibondi, P., Simoncelli, E., Stancampiano, A.: Characterization of a cold atmospheric pressure plasma jet device driven by nanosecond voltage pulses. IEEE Trans. Plasma Sci. 43(3), 713-725 (2015)

43. Sakiyama, Y., Graves, D.B.: Neutral gas flow and ring-shaped emission profile in non-thermal RF-excited plasma needle discharge at atmospheric pressure. Plasma Sources Sci. Technol. 18(2), 025022 (2009)

44. Mulley, R.: Flow of Industrial Fluids: Theory and Equations. CRC Press, Boca Raton (2004)

45. Zhang, Q., Liang, Y., Feng, H., Ma, R.: A study of oxidative stress induced by non-thermal plasma-activated water for bacterial damage. Appl. Phys. Lett. 102, 203701 (2013)

46. Liu, D.-X., Rong, M.-Z., Wang, X.-H., Iza, F., Kong, M.G., Bruggeman, P.: Main species and physicochemical processes in cold atmospheric pressure $\mathrm{He}+\mathrm{O} 2$ plasmas. Plasma Process Polym 7, 846-865 (2010)

47. Laroussi, M.: Nonthermal decontamination of biological media by atmospheric pressure plasmas: review, analysis, and prospects. IEEE Trans. Plasma Sci. 30, 1409-1415 (2002)

48. Stoffels, E., Sakiyama, Y., Graves, D.: Cold atmospheric plasma: charged species and their interactions with cells and tissues. IEEE Trans. Plasma Sci. 36, 1441-1457 (2008)

49. Goosen, N., Moolenaar, G.F.: Repair of UV damage in bacteria. DNA Repair 7, 353-379 (2008)

50. Niemz, M.H.: Laser-Tissue Interactions: Fundamentals and Applications. Springer, Berlin (2013)

51. Kong, M., Kroesen, G., Morfill, G., Nosenko, T., Shimizu, T., van Dijk, J., Zimmermann, J.: Plasma medicine: an introductory review. New J. Phys. 11, 115012 (2009) 
52. Han, L., Patil, S., Boehm, D., Milosavljević, V., Cullen, P.J., Bourke, P.: Mechanisms of inactivation by high-voltage atmospheric cold plasma differ for Escherichia coli and Staphylococcus aureus. Appl. Environ. Microbiol. 82, 450-458 (2016)

53. Mai-Prochnow, A., Clauson, M., Hong, J., Murphy, A.B.: Gram positive and Gram negative bacteria differ in their sensitivity to cold plasma. Sci. Rep. 6, 38610 (2016)

54. Lunov, O., Zablotskii, V., Churpita, O., Chanova, E., Sykova, E., Dejneka, A., Kubinova, S.: Cell death induced by ozone and various non-thermal plasmas: therapeutic perspectives and limitations. Sci. Rep. 4, 7129 (2014)

Publisher's Note Springer Nature remains neutral with regard to jurisdictional claims in published maps and institutional affiliations. 